Provided for non-commercial research and education use. Not for reproduction, distribution or commercial use.

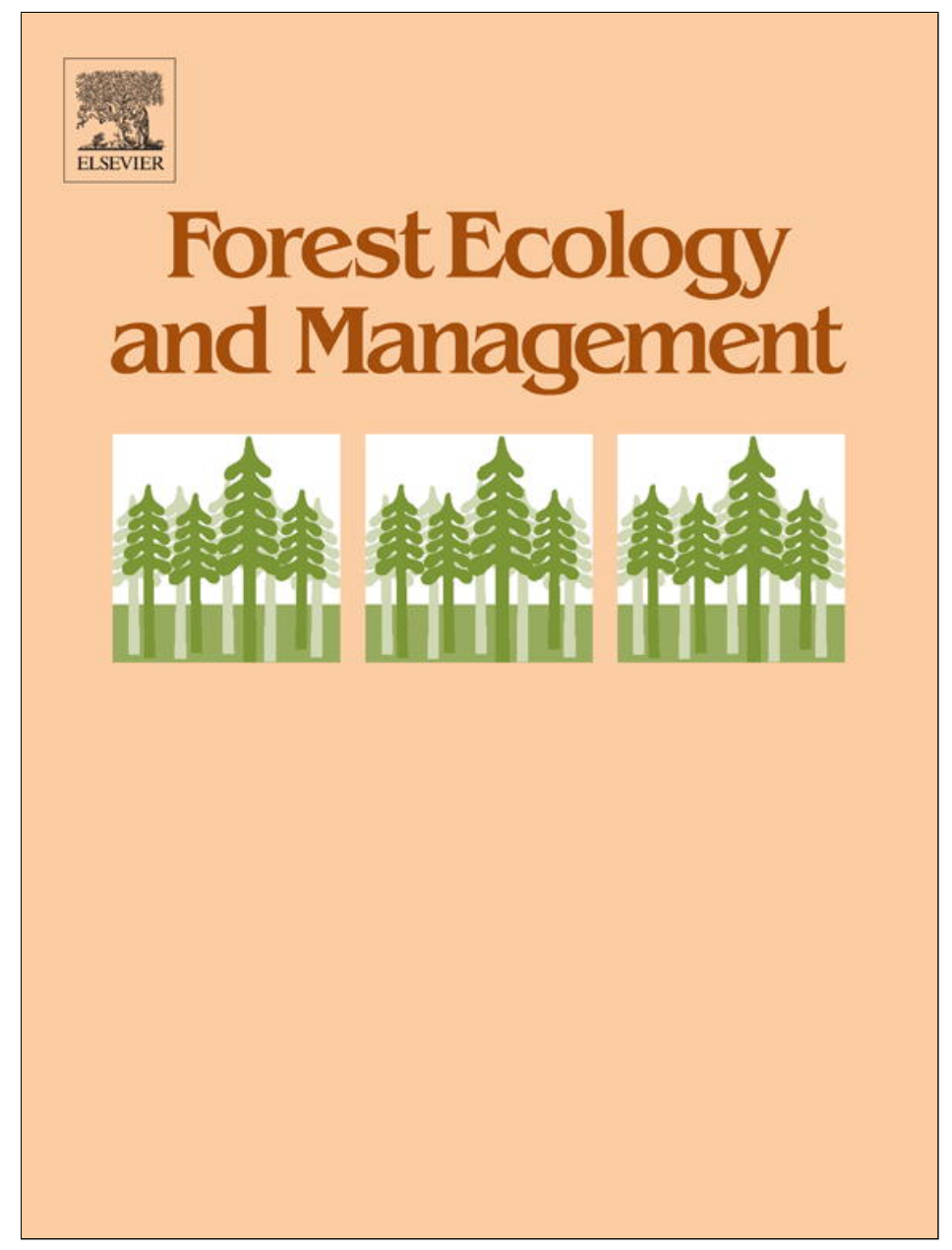

This article appeared in a journal published by Elsevier. The attached copy is furnished to the author for internal non-commercial research and education use, including for instruction at the authors institution and sharing with colleagues.

Other uses, including reproduction and distribution, or selling or licensing copies, or posting to personal, institutional or third party websites are prohibited.

In most cases authors are permitted to post their version of the article (e.g. in Word or Tex form) to their personal website or institutional repository. Authors requiring further information regarding Elsevier's archiving and manuscript policies are encouraged to visit:

http://www.elsevier.com/authorsrights 


\title{
A comparison of times series approaches for dendroecological reconstructions of past canopy disturbance events
}

\author{
Daniel L. Druckenbrod ${ }^{\mathrm{a}, *}$, Neil Pederson ${ }^{\mathrm{b}}$, James Rentch ${ }^{\mathrm{c}}$, Edward R. Cook ${ }^{\mathrm{b}}$ \\ a Department of Geological, Environmental and Marine Sciences, Rider University, 2083 Lawrenceville Road, Lawrenceville, NJ 08648-3099, United States \\ ${ }^{\mathrm{b}}$ Tree Ring Laboratory of Lamont-Doherty Earth Observatory of Columbia University, Palisades, NY 10964, United States \\ ${ }^{\mathrm{c}}$ Division of Forestry and Natural Resources, 344 Percival Hall, West Virginia University, Morgantown, WV 26506-6125, United States
}

\section{A R T I C L E I N F O}

\section{Article history:}

Received 26 October 2012

Received in revised form 19 March 2013

Accepted 22 March 2013

\section{Keywords:}

Dendroecology

Tree-ring analysis

Canopy disturbance events

Forest thinning studies

Carbon sequestration

\begin{abstract}
A B S T R A C T
Time series analysis can identify outliers in tree-ring widths that may not only indicate past disturbances, but may also estimate the subsequent effects of these disturbances on tree growth. Finding a way to isolate these disturbance signals from tree-ring time series could have broad applications in forest ecology and management. Time series outliers may be expressed as pulse, step, or trend interventions, but few dendroecological studies have explored how well these different types of interventions express the response of tree-ring widths to a canopy disturbance resulting in a release event. This study addresses that question by comparing two different time series approaches for detecting release events: a pulse intervention approach and a new combined step and trend (CST) intervention approach. These methods are tested against tree-ring collections with known historical canopy disturbance events: northern red oaks (Quercus rubra) in New York released by the chestnut blight during the early 1920s, eastern hemlocks (Tsuga canadensis) in Pennsylvania released by adjacent selective logging in 1910, and northern red oaks and chestnut oaks (Quercus montana) in West Virginia released through an experimental thinning in 1982. Clusters of CST interventions, but not pulse interventions, were detected for all three collections during and immediately after the known disturbance events, showing that a CST intervention approach consistently reconstructs these release events. In addition, a CST intervention approach isolated canopy disturbance signals from tree-ring widths as disturbance-growth indices. Detrending disturbances from tree-ring widths provides an alternative approach to reconstruct climate in closed-canopy forests; however, just as importantly, disturbance-growth indices created through this method can also reconstruct changes in tree growth rates, biomass, or carbon resulting from a past disturbance event or forest thinning.
\end{abstract}

(c) 2013 Elsevier B.V. All rights reserved.

\section{Introduction}

Tree-ring data provide a valuable ecological record of biological responses to environmental factors in regions where the annual growth increments of trees can be crossdated to calendar years (Speer, 2010). The factors affecting tree growth have been described conceptually by Graybill (1982) and Cook (1987) as a linear aggregate model: $R_{t}=A_{t}+C_{t}+\delta D 1_{t}+\delta D 2_{t}+E_{t}$ where a ring width $\left(R_{t}\right)$ varies with a biological age-size trend $\left(A_{t}\right)$, climate $\left(C_{t}\right)$, endogenous $\left(\delta D 1_{t}\right)$ and exogenous $\left(\delta D 2_{t}\right)$ disturbance events, and other unexplained variation $\left(E_{t}\right)$. $\delta$ denotes whether discrete disturbance events (sensuWhite and Pickett, 1985) are either present $(\delta=1)$ or absent $(\delta=0)$ during a particular year. Endogenous disturbance

\footnotetext{
* Corresponding author. Tel.: +1 609895 5422; fax: +1 6098955782.

E-mail addresses: ddruckenbrod@rider.edu (D.L. Druckenbrod), adk@ldeo. columbia.edu (N. Pederson), jrentch2@wvu.edu (J. Rentch), drdendro@ldeo. columbia.edu (E.R. Cook).
}

events occur at a local scale within a forest, e.g., gap dynamics, while exogenous disturbance events occur from larger-scale processes impacting an entire stand, e.g., windthrow from a hurricane (Cook, 1990). Isolating these component factors enables reconstructions of past environmental change that can inform how trees and forests will respond to future environmental change.

In dendroclimatology, this conceptual approach has been applied to closed-canopy forests to reconstruct past climate from tree rings typically using a negative exponential or linear regression equation to account for $A_{t}$ (Cook and Kairiukstis, 1990). Smoothing splines (Cook and Peters, 1981) are then effective in removing the competitive effects from disturbance events, $\delta D 1_{t}$ or $\delta D 2_{t}$, on growth rates (Blasing et al., 1983); however, they have not been considered to represent a record of disturbance events.

Largely independently, dendroecological methods have also been developed to reconstruct past canopy disturbance events using tree rings. As early as the 1920s, studies showed that tree growth rates increased for surviving trees after a canopy 
disturbance (Marshall, 1927; Stephens, 1956; Woods and Shanks, 1959; Henry and Swan, 1974; Oliver and Stephens, 1977). Lorimer and Frelich (1989) defined quantitative criteria for canopy release events using the percentage change in growth rates (\%GC) before and after a disturbance event. The magnitude of these release events could either be moderate $(50-99 \%)$ or major $(>100 \%)$ and their duration could be temporary (10-15 years) or sustained ( $>15$ years). Nowacki and Abrams (1997) extended this approach to identify disturbance events using a threshold of a $25 \%$ increase in sequential 10-year running means of growth rates based on oak (Quercus spp.) thinning studies and an assumption that tree growth is sensitive to climate variation generally at shorter time scales. This method, commonly referred to as radial growth averaging, has become widely applied in the reconstruction of forest histories (Rubino and McCarthy, 2004) involving different species and regions and has led to further adaptations (e.g. Black and Abrams, 2003; Fraver and White, 2005).

In addition to its use of detrending, dendroclimatology also historically differs from dendroecology in its treatment of the autocorrelation typically present within series of tree-ring width measurements. Autocorrelation in tree-ring widths arises from both biological processes of tree growth (Fritts, 1976) and underlying autocorrelation in the climate system that could affect tree growth (Lund et al., 2007). As a result, adjacent tree-ring widths are interdependent rather than independent values, which reduces their effective sample size (Fritts, 1976). This autocorrelated signal is further magnified when a series of tree-ring widths is subjected to a running mean (Fritts, 1976). Previous studies (e.g., Cook, 1985; Guiot, 1986; Monserud, 1986) have found that ring-width measurements may typically be expressed as autoregressive (AR) processes or by moving average (MA) processes (sensuBox and Jenkins, 1970), which differ mathematically from the use of running means by Nowacki and Abrams (1997). Estimating and removing autocorrelation generates a time series of independent events that may then be applied to statistical tests to determine relationships to factors such as climate. Using detrending and AR modeling, dendroclimatology has successfully reconstructed climate variation in eastern North America (e.g., Cook and Jacoby, 1977; Pederson et al., 2012; Stahle and Cleaveland, 1992) as well as in other closed-canopy forest regions (e.g., Büntgen et al., 2011; Buckley et al., 2010; Cook et al., 1992; Wilson et al., 2005).

Therefore, the aim of this study is to demonstrate the potential of established dendroclimatic detrending and AR modeling approaches for the identification of past canopy disturbance events in dendroecology. This study also builds on the prior statistical research of intervention detection in time series (e.g., Fox, 1972; Box and Tiao, 1975; Chang, 1982). Interventions are any external forcings on particular values of a time series model and may be identified as outliers that depart from the predictions of the model. These methods are well suited for identifying abrupt changes in ecosystems in general, but methods like these have been underutilized in ecology (Andersen et al., 2009). Even though the limited applications of intervention detection to tree rings have demonstrated that intervention detection can identify past disturbance events (e.g., Downing and McLaughlin, 1990: Mäkinen, 1997; Pedersen, 1998; Druckenbrod, 2005; Magnussen and Alfaro, 2012), there is a need for a further exploration of the type of intervention (pulse, step, or trend) that best characterizes a canopy release.

Accordingly, the first objective of this study is to compare a pulse intervention detection method with an example of a new combined step and trend (CST) intervention detection method. For trees within the closed-canopy forests, as in eastern North America, we hypothesize that changes in growth rates resulting from canopy disturbance events are more effectively characterized by CST interventions than pulse interventions. Since suppression and release episodes in the forest canopy typically extend over multiple years, we expect that pulse interventions characterize other disturbance events with only an annual duration.

As a second objective, we also intend to show that in addition to identifying the approximate initiation year of these disturbance events, time series methods may also characterize other effects of the disturbance event on surviving trees, including the magnitude and the duration of a resulting growth release. Knowing these characteristics enables the isolation of a disturbance signal which can be averaged with other cores from a chronology to construct a site-wide signal that may consist of endogenous or exogenous disturbance events through time. This disturbance signal differs from disturbance chronologies (sensu Lorimer and Frelich, 1989) in that it is more than simply a record of the initiation years of various canopy disturbances that comprise a disturbance chronology. The new method proposed here also records how those disturbances modified the subsequent growth of a tree through time. Further, characterizing a canopy disturbance signal also potentially enables detrending of this factor from ring widths through time, minimizing the impact of stand dynamics, which can confound dendroclimatic reconstructions for these closed-canopy forests.

As a final objective, we propose that a time series approach has the potential to bridge a divide between dendroclimatology and dendroecology that would enable more complementary analyses of tree-ring series. By using the same detrending and statistical methods that guide dendroclimatology, a time-series dendroecological approach provides a means to possibly decompose the variance of a tree-ring series into a set of independent factors $\left(A_{t}, C_{t}\right.$, $D_{t}$, and $E_{t}$ ) that underlie tree growth through time.

\section{Methods}

\subsection{Study sites and tree-ring chronologies}

Three tree-ring collections from forest stands with canopy disturbance histories known to have experienced release events were chosen for comparison with two times series approaches: a northern red oak (Quercus rubra) collection in New York, an old-growth eastern hemlock (Tsuga canadensis) collection in Pennsylvania; and a northern red oak and chestnut oak (Quercus montana) collection in West Virginia (Table 1). All collections were visually crossdated and verified using COFECHA (Holmes, 1983).

The northern red oak collection was sampled from a stand in Curtiss-Gale Wildlife Management Area (CGWMA) near Fulton, New York that experienced release following salvage logging for American chestnut (Castanea dentata) in the 1920s (City of Fulton Historian, Sean Fagan, pers. comm., 1993). The chestnut blight (Cryphonectria parasitica) was first observed in New York City in 1904 (Anagnostakis and Hillman, 1992). By 1908, it was observed in the southern portion of the New York State (Murrill, 1908) and by $1925,80-100 \%$ of American chestnuts across the state of New York were infected or killed (Gravatt and Gill, 1930; USDA, 1941), including the area of the Curtiss-Gale Wildlife Management Area.

The eastern hemlock collection was sampled in the Hemlocks Natural Area (HNA) within Tuscarora State Forest near Blain, Pennsylvania. The stand experienced selective logging in 1910 (Cook, 1987).

The northern red oak and chestnut oak collection is from a retrospective analysis of forest thinning in 1982 on a 55-year-old hardwood stand in the West Virginia University Research Forest (WVURF) near Morgantown, West Virginia. Rentch et al. (2002) cored trees of these two species in 2000 to determine the sensitivity in lag and \%GC to this experimental treatment. In the original 1982 experiment, experimental units were thinned from below 
Table 1

Summary of tree-ring chronologies from three forest stands impacted by a past canopy disturbance.

\begin{tabular}{|c|c|c|c|c|c|c|}
\hline Forest location & Site code & Species & No. cores & No. trees & Chronology years & Disturbance year \\
\hline Curtiss-Gale Wildlife Management Area, NY & CGWMA & Quercus rubra & 40 & 20 & 1828-2002 & Early 1920 s \\
\hline Hemlocks Natural Area, PA & HNA & Tsuga canadensis & 26 & 14 & $1535-1981$ & 1910 \\
\hline West Virginia University Research Forest, WV & WVURF & $\begin{array}{l}\text { Q. rubra and } \\
\text { Q. montana }\end{array}$ & $\begin{array}{l}86^{\mathrm{a}} \\
51^{\mathrm{b}}\end{array}$ & $\begin{array}{l}44^{\mathrm{a}} \\
26^{b}\end{array}$ & 1923-1999 & 1982 \\
\hline
\end{tabular}

a Number that were in the $0-1$ FTG rating.

b Number that were in the 3-4 FTG rating.

to one of three treatments: $100 \%$ (control), $45 \%, 60 \%$, and $75 \%$ relative density. After five growing seasons, dominant and codominant trees were assigned a free-to-grow (FTG) rating, indicating the number of sides (maximum $=4$ ) of the tree crown that are least $1.5 \mathrm{~m}$ from neighboring trees (Lamson et al., 1990). Tree diameters in this stand were also recorded at 5,10 , and 15 years after thinning across FTG rating classes.

\subsection{Detecting pulse and CST interventions}

This new approach seeks to reconstruct episodes of canopy disturbance by identifying sequences of unusual residual ring widths after accounting for the effects of any biological age trend and autocorrelation. Accordingly, the approach focuses on the basic relationship that residuals are an expression of how well data fit a model (Hoaglin et al., 1983): residual = data - fit. For tree-ring data, detrending and prewhitening minimizes the impact of $A_{t}$ and autocorrelation on a tree-ring time series, respectively, by subtracting the expected 'fit' from the data. Ideally, the resulting residuals are a stationary time series that consists of independent events with constant mean and variance (i.e., white noise, or random 'shocks' as discussed by Box and Jenkins, 1970). Our approach assumes that a sequence of rings where this difference is statistically unusual indicates a disturbance affecting the growth of a tree. Essentially, we are examining sequences of residual ring widths for the presence of uncommonly large, positive or negative mean values that might reflect abrupt changes in the canopy light environment. This approach allows us to identify and remove episodes of poor model fit that may be attributed to canopy release or suppression events.

We introduce this method using an example of a northern red oak ring-width series from CGWMA impacted by the chestnut blight in the 1920s (Fig. 1). To identify canopy disturbance events, this approach begins with the same procedures commonly applied in dendroclimatology for age detrending and AR modeling. First, ring-width values are power transformed to reduce the heteroscedasticity often present in a tree-ring time series. Heteroscedasticity describes how the variance of ring widths generally increases with their mean, making a series nonstationary (Cook and Peters, 1997). The optimal power for this transformation is calculated as: $p=1-m$ where $m$ is the slope of a regression line comparing $\log _{10}$ ring-widths against the $\log _{10}$ of the absolute value of their first differences. For $p<0.05$, a $\log _{10}$ transformation was used instead of a power transformation and for $p>1, p$ was reduced to a value of 1 and a power transformation was applied. Fig. 1B shows the red oak series after power transformation. Similar to dendroclimatological applications, ring-widths values are then age detrended using a negative exponential curve (Fig. 1C). If this curve does not fit the data, then a linear regression is fit instead with either a positive or negative slope. Using the Burg maximum entropy
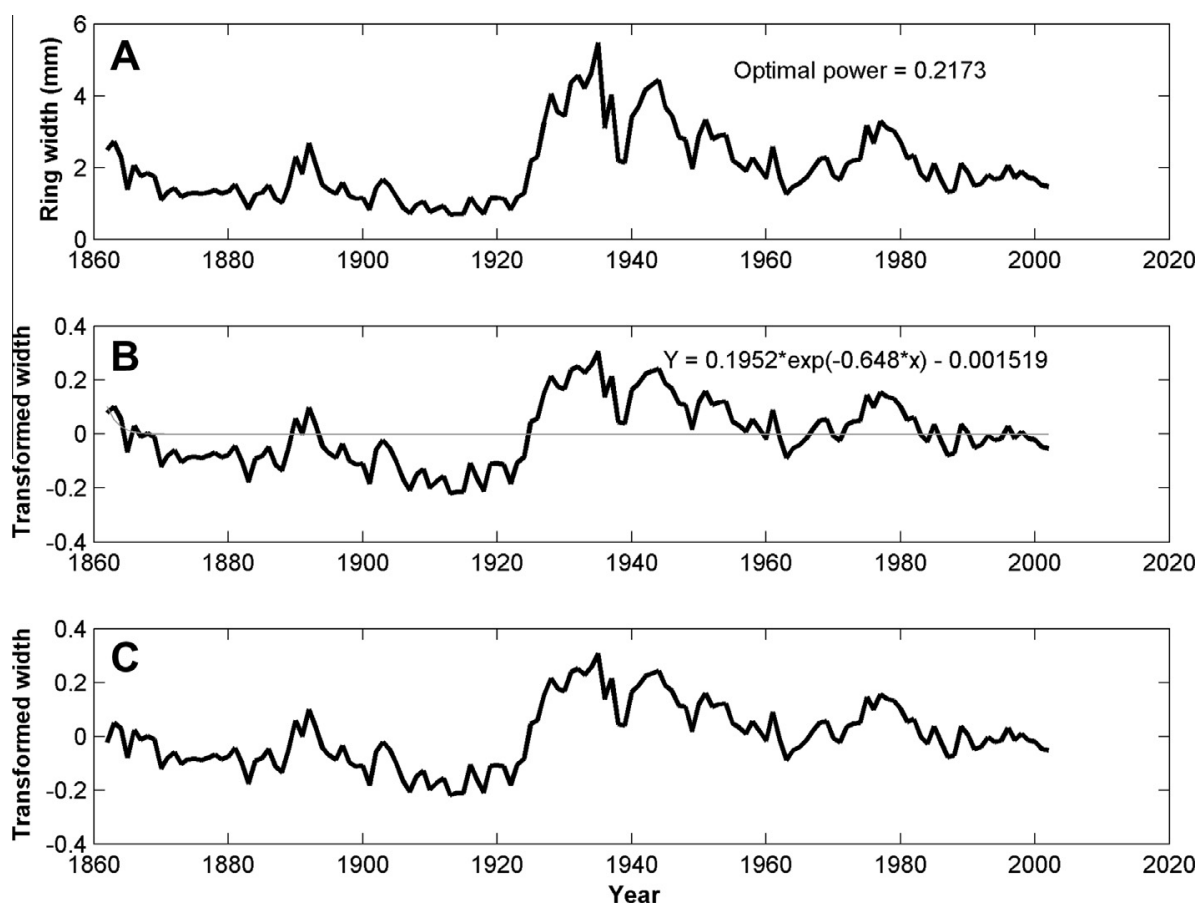

Fig. 1. Ring width measurements of a northern red oak series (ID: CGR10B) released by the chestnut blight in the 1920s in New York (A). Ring widths are power transformed (B) and then the residuals are age detrended (C) with a negative exponential fit (gray line) prior to autoregressive modeling and intervention detection. 

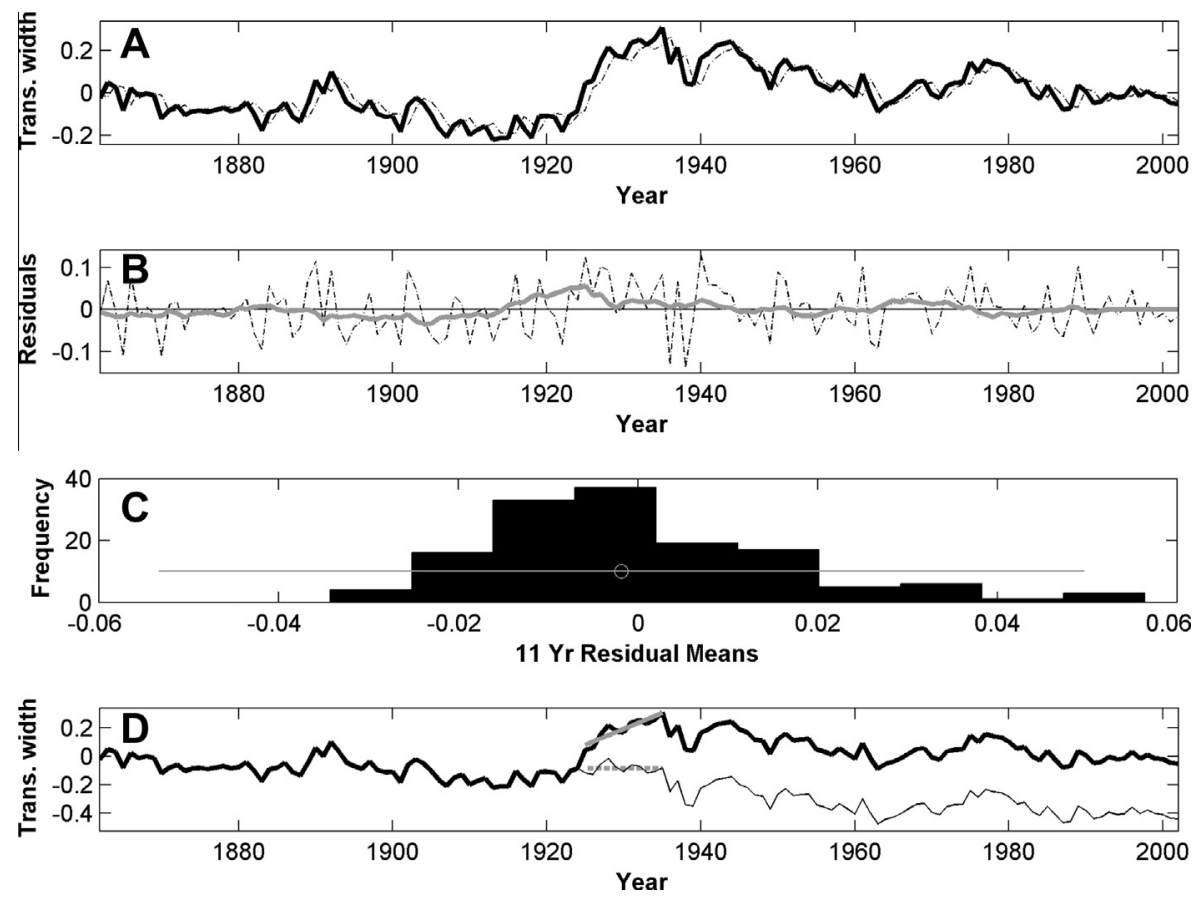

Fig. 2. Detection of combined step and trend interventions in a northern red oak series (ID: CGR10B) released by the chestnut blight in the 1920s in New York. (A) Autoregressive model (dashed line) underestimates ring width values from 1925 to 1935 (11 years). (B) This poor model fit is apparent in the unusual pattern of positive residuals during that time period (dashed line), which is results in a large 11-year running mean (gray line). (C) Following the central limit theorem, this running mean is $>3.29$ deviations (demarcated by length of gray line) from a histogram of all 11-year running means along the series. (D) A linear regression fit to the transformed data in this interval (gray line). The trend during these years is removed and the intercept is set equal to the year prior to the outlier initiation (dashed gray line). Thin line shows the transformed time series with this disturbance event removed (detrended) from the series. No further combined step and trend interventions were detected in this series.

method (Kay, 1988), the AR order ( $p$ ) and values of the transformed, detrended series are estimated. Since residuals for the first $\mathrm{p}$ ring-widths in a series cannot be estimated directly, the series is then modeled inversely (backcasted) so that residuals are generated from all ring-width values in a series (Fig. 2A).

To detect pulse interventions, one could examine these residuals for single-year outliers greater than a specified standard deviation from the mean of the residuals in a series. This procedure is implemented in ARSTAN, a tree-ring detrending program often used in dendroclimatology (Cook and Krusic, 2011) and used in our analyses of pulse interventions in this study. If one or more pulse interventions are identified, their years are recorded and the residuals for those years are set to 0 . The AR model is then re-estimated on the next iteration with these new downweighted residuals to determine if any additional outliers will be detected. For our example northern red oak series, one negative pulse outlier is detected in 1865 using this method.

However, one can extend the pulse detection approach to also identify multiyear periods of statistically unusual growth by examining the residuals of sets of successive ring widths instead of individual ring widths. A description of the code for this procedure is presented in the Supplemental Materials (Appendix D) based on code written in Matlab (Mathworks, 2011). Even though ring widths and their AR residuals may not always follow a Gaussian distribution, the central limit theorem (Zar, 1996) states that sample means from a non-Gaussian distribution will trend toward Gaussian. Thus, one could take running means of the residuals (which are now independent observations due to age detrending and prewhitening) at a particular window length and generate a distribution of means that approaches a Gaussian shape. Outliers from this distribution occur when the AR model either underestimates or overestimates the expected growth for a set of successive years (i.e., when the AR model lags behind as the ring widths either increase or decrease abruptly for a particular time period). These outliers thus indicate a change in mean or trend for a tree-ring series. Underestimated AR model sequences occur when an unusually high (positive) set of successive residuals remains after detrending and prewhitening while overestimated sequences occur when an unusually low (negative) set of residuals remain. Thus consecutive positive residuals from the AR model may correspond to growth releases recorded in tree-ring widths, while consecutive negative residuals may correspond to growth suppressions.

Since the resulting running-mean residuals may only approximate a Gaussian distribution in some cases, the mean and standard deviation of a sample is determined using Tukey's bi-weight mean and scale (where scale is a robust equivalent to the standard deviation), which have a greater robustness of efficiency across data with different distributions (Hoaglin et al., 1983). For this study, a sequence of residuals is considered an outlier if it lies outside Tukey's bi-weight mean with a scale of 3.29. Using this definition, this residual sequence would lie outside of $99.9 \%$ of the observed residuals means in the distribution.

As the window length for the running means does not need to be limited to one value, one can test for outliers from sample distributions calculated at varying window lengths. For example, given a tree-ring series of $\mathrm{n}$ years, a reasonable expectation might be to evaluate distributions from window lengths at a minimum of 9 years to a maximum of $n / 3$. An $n / 3$ length allows for sufficient sample size of running-mean residuals to test the central limit theorem distribution. Given a sequence of residuals that are identified as outliers, the most extreme running mean of residuals across all window lengths identifies the time period of a CST intervention in the series. Evaluating moving windows across this range enables the approach to determine not only the year at which the multiyear period of unusual growth begins, but also the window length that best captures its duration. This variable range in window length is important because even though 10 years is typically considered the time frame under which oak trees respond to canopy 
disturbances, an increased growth response has been observed to persist for up to 20 years in white oaks (Schlesinger, 1978).

For our example northern red oak series, an 11-year running mean of the residuals (Fig. 2B) shows an unusually large set of positive residual values beginning in 1925 . This mean is greater than 3.29 deviations from the distribution of all 11-year running means of residuals for this series using Tukey's bi-weight mean and sigma (Fig. 2C).

As in the pulse detection method, the detection of a CST intervention also proceeds iteratively, but this method identifies the most extreme positive or negative sample mean across all possible window lengths in a time series. Similar to the ability of time series analysis to identify the year and magnitude of pulse interventions, it is also possible to calculate the magnitude of the CST intervention by fitting a linear regression to the transformed time series for the years identified as outliers by the central limit distribution. With each iteration, any CST intervention, where the step is defined by the regression line's intercept and the trend by its slope, forms a portion of the disturbance signal for that series. These CST interventions are subtracted from the series prior to the next iteration, incrementally producing a standardized series from the transformed and age-detrended data series. Fig. 2D shows how the 11-year growth release is detrended from the example northern red oak series after the first iteration. The second iteration found no additional CST interventions.

At this point, the standardized series has both $A_{t}$ and $D_{t}$ signals largely removed since the series, which was previously transformed and age detrended, has now also been disturbance detrended. The standardized series provides an approximation of tree growth in the absence of suppression and release episodes (Fig. 3). Fig. 4 summarizes a different example where the first two iterations detected CST interventions; a positive intervention in 1924 for 9 years and then a negative CST intervention in 1948 for 19 years. Appendices A, B, and C in the Supplemental Materials provide further examples of series, including some with multiple positive and negative CST interventions detected. After identifying all significant CST interventions, the standardized series can then be re-expressed in original units.

The difference between the initial series and the resulting standardized series (with its age trend restored) is a disturbance growth index that expresses the disturbance signal in original units. An increasing index indicates that positive CST interventions are expressing an increased growth response to a disturbance and its subsequent elevated growth rates. Conversely, a decreasing index indicates a decreased growth response and its subsequent reduced growth rates. For the example northern red oak series in Fig. 3, the disturbance growth index resulting from the positive CST intervention in 1925 led to a total additional growth increment of $157 \mathrm{~mm}$ when compared to the standardized series assuming the tree would have survived until 2003 without a canopy release. The standardized series of this northern red oak core is also less heteroscedastic than the original series because the series was detrended in transformed units. Re-expressing those values in original units leads to lower variation during the disturbance time period. In order to compare across a collection, a mean disturbance growth index then averages all disturbance growth indices from individual cores that detected at least one positive or negative CST intervention. The total change in growth from a disturbance event (additional mean diameter increment) can also be determined by subtracting the mean disturbance growth index value prior to the event year from values in subsequent years.

\subsection{Descriptive statistical analysis}

In order to express the results in a manner similar to previous dendroecological reconstructions, disturbance history chronologies of positive and negative CST interventions through time were created for each collection. CST interventions were shown for the year the event began. For example, in Fig. 2 the CST intervention would be included as an event only in 1925 even though it continues through 1935. In contrast, disturbance growth indices can incorporate the initiation, duration, and magnitude of the disturbance response for individual series. Disturbance growth indices can also indicate the magnitude of the disturbance event on subsequent growth rates by providing an estimate of increased (or decreased) diameter growth per year resulting from positive (or negative) CST interventions. Using allometric equations to estimate aboveground biomass, these growth rates can then be re-expressed into other variables like kilograms of carbon stored per year per disturbance and non-disturbance series. This information will be useful for forest management because it gives insight into the efficacy of management techniques versus other influences on tree growth. For example, a recent study indicates that significant drought nearly reduces carbon uptake as much as logging (Davis et al., 2009).

\section{Results}

Disturbance histories for these three stands were summarized both by traditional disturbance chronologies and by mean disturbance growth indices (comprised of only CST interventions, not pulse interventions). The northern red oak collection in New York (CGWMA) shows an increase in the number of positive CST interventions beginning in the early 1920s, coincident with the historical salvage logging of chestnut (Fig. 5B). This increase is also reflected in the mean disturbance growth index for the chronology, showing an increase beginning in 1923 and ending in 2000 that sums to a total of $150 \mathrm{~mm}$ of additional mean diameter growth

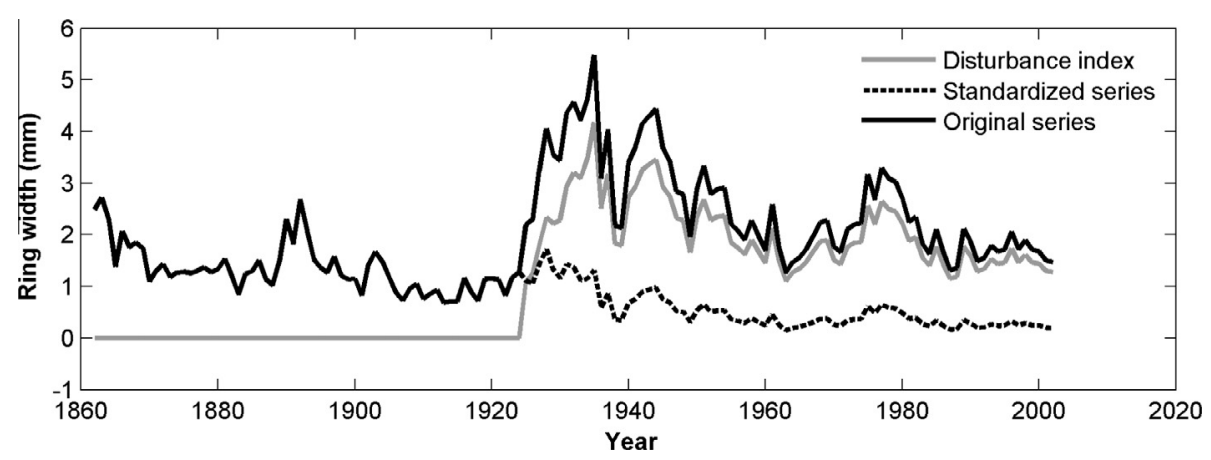

Fig. 3. Identification and standardization of a combined step and trend intervention in a northern red oak series (ID: CGR10B) released by the chestnut blight in the 1920s in New York. Only the first iteration in this series detected a combined step and trend intervention. The standardized series shown here has been re-expressed with its age trend and in units of $\mathrm{mm}$ for comparison with the original ring-width measurements. 


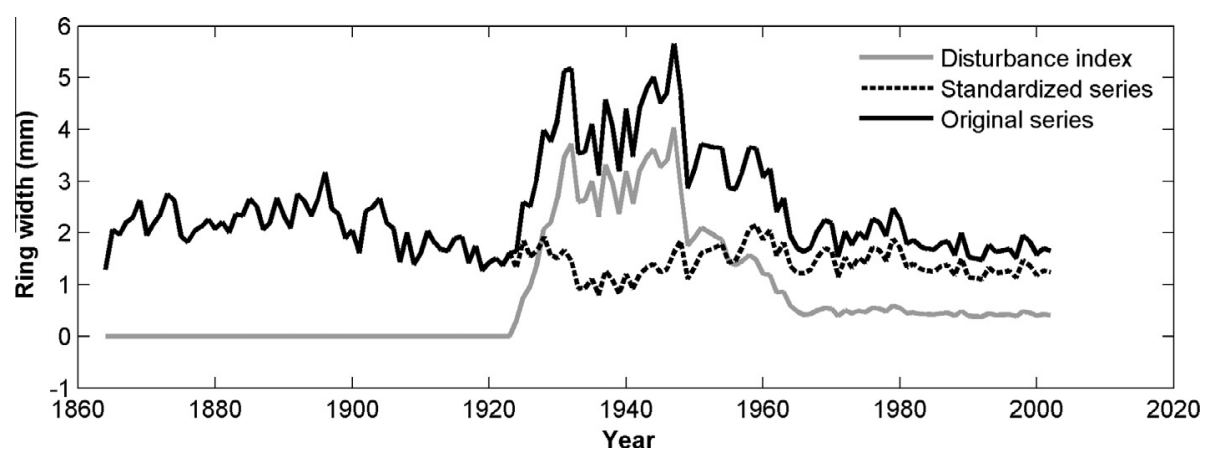

Fig. 4. Identification and standardization of combined step and trend interventions in a northern red oak series (ID: CGR14B) released by the chestnut blight in the 1920s in New York. The first iteration in this series detected a positive intervention in 1924 for 9 years and the second iteration detected a negative intervention in 1948 for 19 years. The standardized series shown here has been re-expressed with its age trend and in units of mm for comparison with the original ring-width measurements.
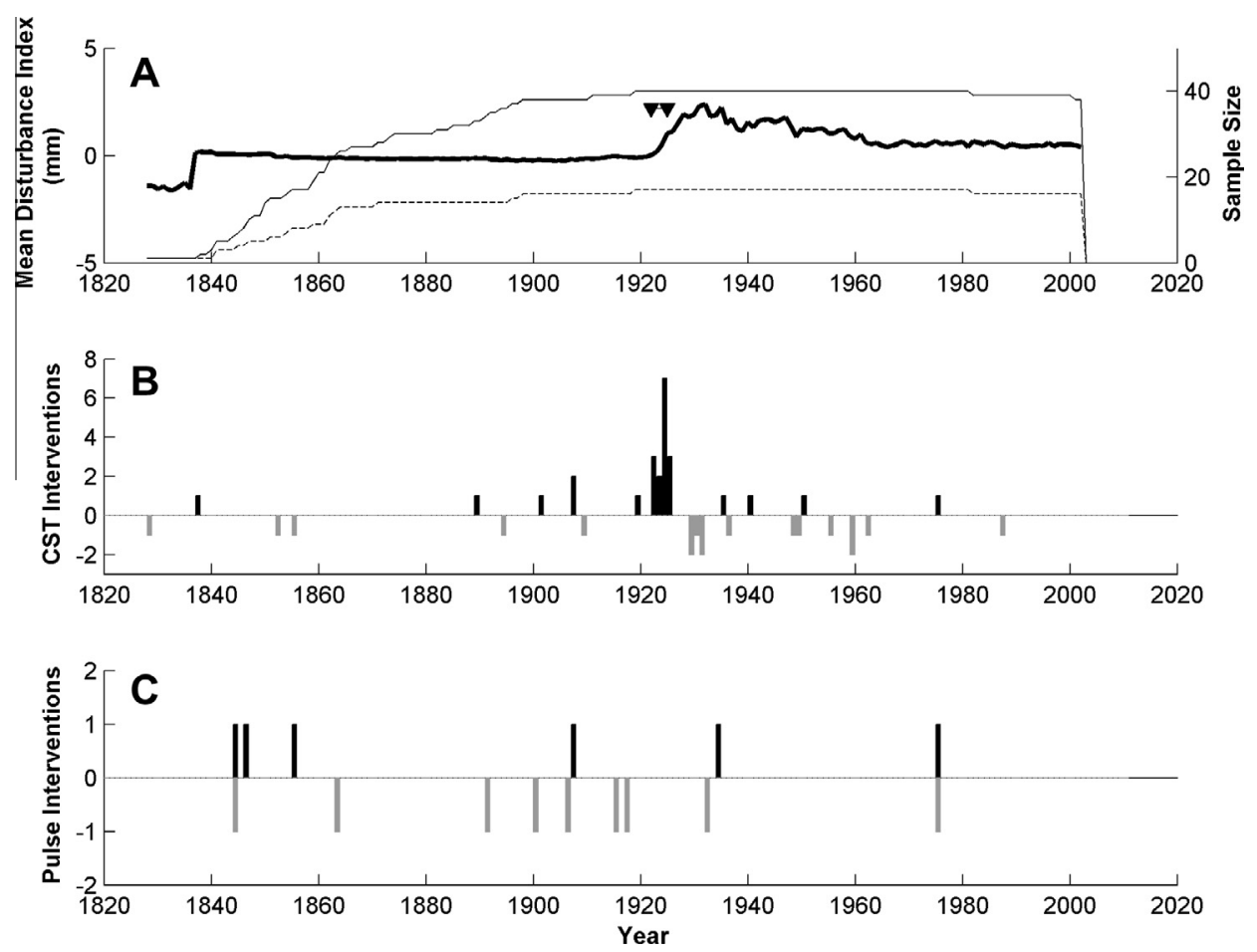

Fig. 5. (A) Mean disturbance growth index across all cores in a northern red oak chronology released by the chestnut blight in the 1920s in New York (thick black line) with chronology sample size (thin line) and subset of chronology containing combined step and trend interventions (dashed line). Triangles denote known disturbance period (approximately 1922-1925). (B) Number of combined step and trend interventions through time by initial year of intervention. (C) Number of pulse interventions through time. Positive interventions are shown in black and negative in gray.

for the subset of trees with CST interventions (Fig. 5A). The increase in mean index value during the 1830 s may be a more localized disturbance event since the sample size was small during that period, but the concurrent increase in sample size of cores at this time suggests that this event does correspond to an earlier disturbance. There is also a set of negative CST interventions in the early 1930s approximately a decade after the logging event. Unlike the CST intervention results, there is no cluster of positive pulse interventions detected by ARSTAN during the 1920s (Fig. 5C).

The hemlock collection in Pennsylvania (HNA) shows an increase in CST interventions and an increase in the mean disturbance growth index after the 1910 logging (Fig. 6A and B). The total additional mean diameter increment for these trees with CST interventions is $46 \mathrm{~mm}$ between 1910 and 1981. Pulse interventions are not more frequent after this disturbance (Fig. 6C). An earlier unrecorded disturbance may have also occurred in this stand ca. 1700 with the increase in CST interventions, mean disturbance growth index, and number of cores at that time.

The chestnut oak and red oak cores from West Virginia (WVURF) from the 0 (control) and 1 FTG canopy exposure thinning exhibit no increase in CST interventions, mean disturbance growth index, or pulse interventions (Fig. 7); however, the mean disturbance chronology decreases beginning around 1960. In contrast, cores collected from trees with FTG ratings of 3 and 4 show 12 positive CST interventions from 10 trees beginning within a few years before and after the 1982 thinning (Fig. 8A and B). Of these 12 interventions, 4 initiate during the years 1977-1979, preceding the thinning event, but incorporating it within the duration of the intervention. The mean disturbance growth index also begins increasing subsequent to this thinning, although it also showed an earlier decrease starting around 1960. A small set of pulse interventions was also detected subsequent to this thinning (Fig. 8C). 

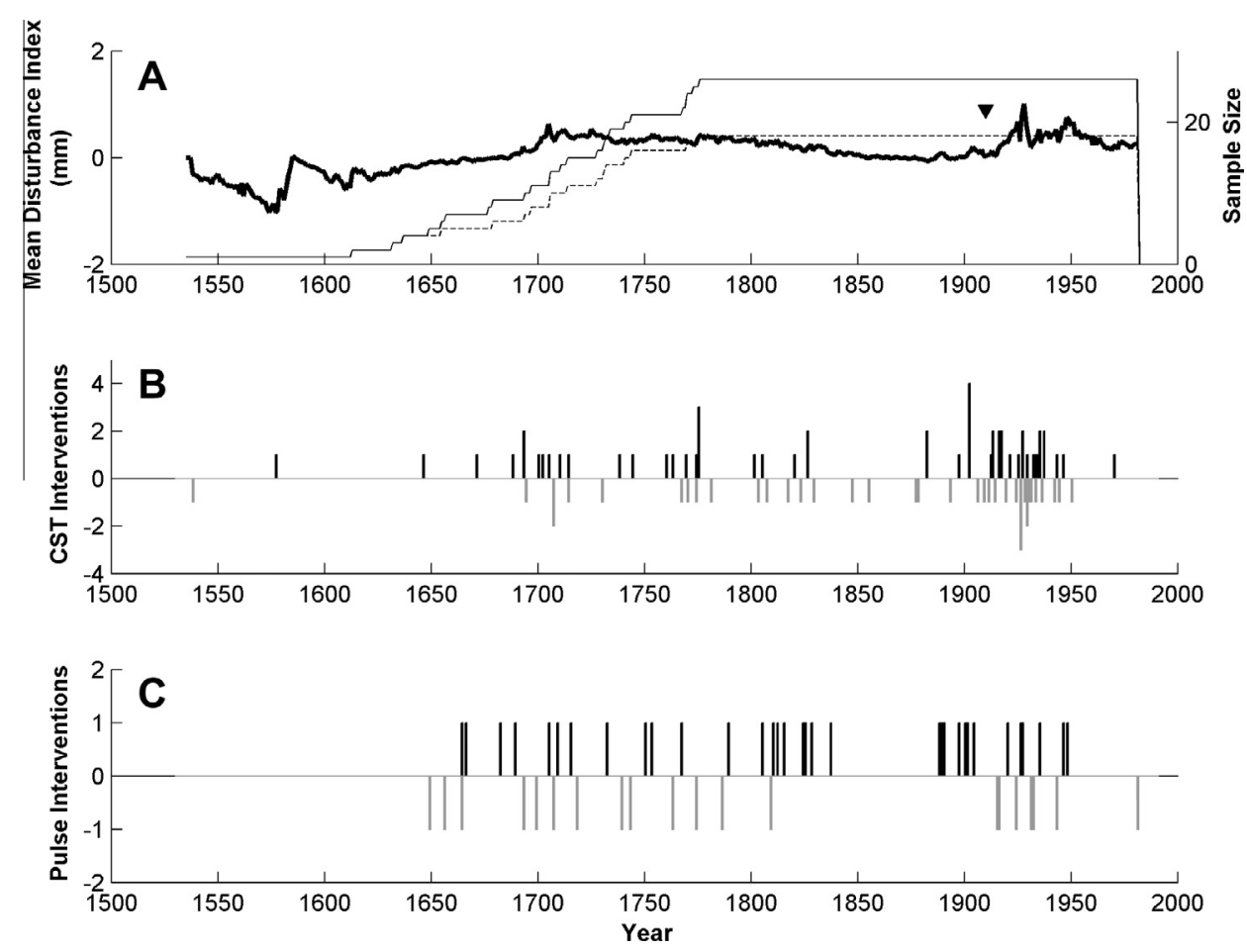

Fig. 6. (A) Mean disturbance growth index across all cores in a eastern hemlock chronology released by selective logging around 1910 in Pennsylvania (thick black line) with chronology sample size (thin line) and subset of chronology containing combined step and trend interventions (dashed line). Triangle denotes known disturbance year (approximately 1910). (B) Number of combined step and trend interventions through time by initial year of outlier. (C) Number of pulse interventions through time. Positive interventions are shown in black and negative in gray.
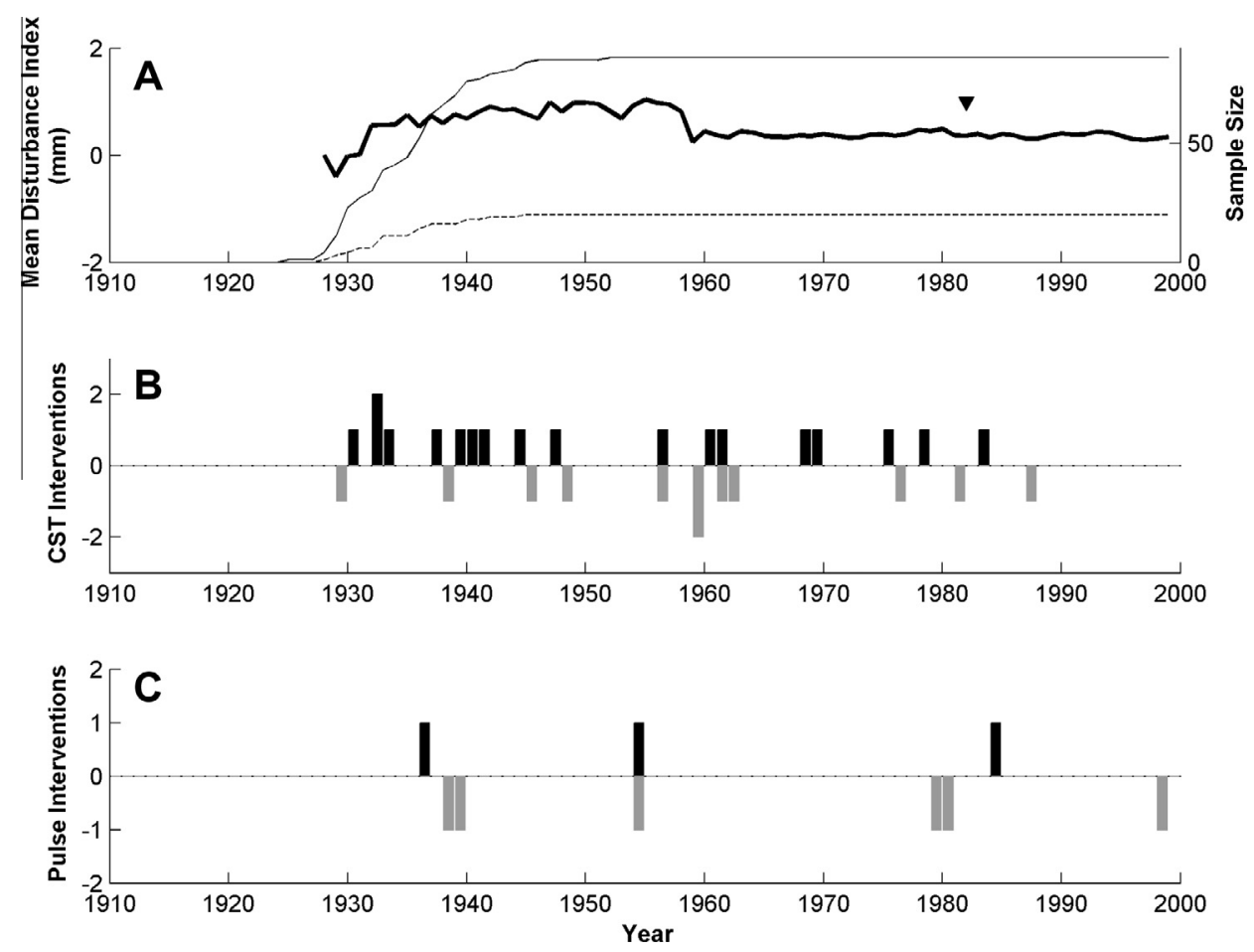

Fig. 7. (A) Mean disturbance growth index across all cores in a chestnut oak and northern red oak chronology in a 'thinning from below' experiment (thick black line) with chronology sample size (thin line) and subset of chronology containing combined step and trend interventions (dashed line). This 1982 thinning left trees with 0 (control) to 1 side of their canopy free to grow. Triangle denotes known disturbance year (1982). (B) Number of combined step and trend interventions through time by initial year of outlier. (C) Number of pulse interventions through time. Positive interventions are shown in black and negative in gray. 

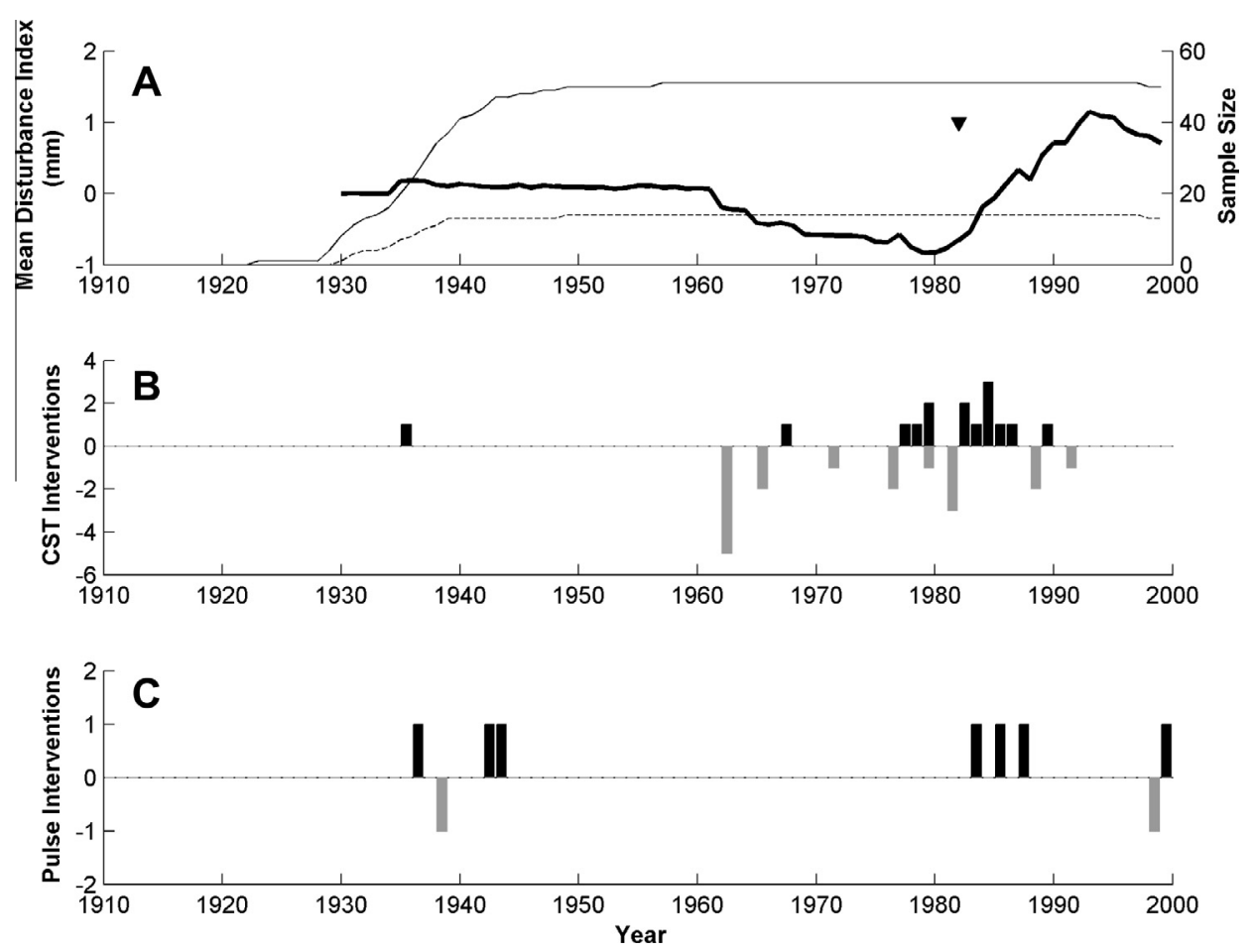

Fig. 8. (A) Mean disturbance growth index across all cores in a chestnut oak and northern red oak chronology in a 'thinning from below' experiment (thick black line) with chronology sample size (thin line) and subset of chronology containing combined step and trend interventions (dashed line). The 1982 thinning left trees with 3-4 sides (100\%) of their canopy free to grow. Triangle denotes known disturbance year (1982). (B) Number of combined step and trend interventions through time by initial year of outlier. (C) Number of pulse interventions through time. Positive interventions are shown in black and negative in gray.

Table 2

Average diameter measurements $(\mathrm{cm})$ of chestnut oak and northern red oak trees at the WV hardwood stand compared with estimates of average additional growth increment $(\mathrm{cm})$ detected from 10 trees (free-to-grow ratings from 3 to 4 ) with positive combined step and trend interventions ca. 1982.

\begin{tabular}{|c|c|c|c|c|}
\hline & \multirow[t]{2}{*}{ DBH prior to thinning } & \multicolumn{3}{|c|}{ Increment by years after thinning treatmen } \\
\hline & & 5 years & 10 years & 15 years \\
\hline FTG 0 tree diameters ( $n=81$ trees) & 26.3 & 1.9 & 3.5 & 5.8 \\
\hline FTG 3-4 tree diameters with positive CST interventions ca. $1982(n=10)$ & 29.4 & 2.5 & 5.9 & 9.8 \\
\hline Additional increment observed from DBH difference & & 0.7 & 2.4 & 4.0 \\
\hline Additional increment observed from detection of 12 positive CST interventions ca. 1982 & & 0.6 & 1.9 & 3.5 \\
\hline
\end{tabular}

Repeated diameter measurements can also be used as a comparison on the estimates of the disturbance magnitude estimated from CST interventions for trees with FTG ratings of 3-4 (Table 2). After accounting for the difference in diameters prior to the thinning, this diameter data can be used to determine the average diameter increase of the 10 trees with positive CST interventions relative to the control trees $(\mathrm{FTG}=0)$ through time. Only a $1 \mathrm{~mm}$ difference was found five years after thinning between the DBH increment and the estimate from the positive CST interventions.

\section{Discussion}

Across all three tree-ring collections, CST interventions consistently indicated the known historical canopy disturbance events more clearly than pulse interventions. The multiyear duration of these growth responses make them more suited to detection by CST interventions than pulse interventions. CST interventions summarized into mean disturbance growth indices also more accurately characterized the year of the known disturbance event (as characterized by a change in the trend of the mean disturbance growth index) than when summarized into the more commonly used time-series of disturbance chronologies. For example, the disturbance chronologies for the hemlock stand (HNA) and the 3 and 4 FTG rated hardwood stand (WVURF) both had some positive CST interventions that preceded the known disturbance by a few years. The particular initiation year of CST interventions occasionally appears sensitive to shorter term variation in ring widths. For example, the experimentally thinned trees at WVURF had an above average growth year in 1978 (Rentch et al., 2002), which may have been incorporated in the outlier sequence for the subset of cores that had CST interventions beginning in the late 1970s. Overall though this approach accurately and conservatively reconstructs these known events with few sets of CST interventions recorded from these three stands at other points in time.

\subsection{Limitations of the CST intervention method}

For many trees in each collection, CST interventions are not identified near the time of the known canopy disturbance. While not all cores in these collections appear to show release events with visual inspections, it is likely that the conservative character of this approach is susceptible to Type II errors. However, this method seldom detects CST interventions during other years and thus likely commits few Type I errors. The potential for fewer Type 
I errors is evidenced by the lack of CST interventions for trees with FTG ratings of 0 and 1 . A more formal error analysis is planned for this method and would better characterize any tendency to incorrectly identify disturbance events. One potential approach for detecting more CST interventions in a collection would be to fit the resulting mean disturbance growth index as a regressor to each ring-width series to determine whether it accounts for a significant component of the variance through time. If the mean disturbance growth index is a significant predictor of a portion of the variance in growth for a tree within the same stand, then the growth of that tree may have been affected by the same disturbance events as the other trees with CST interventions in the stand.

Of the three collections, WVURF is the most challenging because the sampled trees were already co-dominant prior to the experiment and the thinning experiment in this stand largely removed trees of subordinate canopy status. Rentch et al. (2002) showed that canopy trees in this stand were less sensitive to changes in competition when subcanopy trees were removed. Similarly, a review by Nowacki and Abrams (1997) for other oak experiments indicated that canopy oaks have small responses if roughly $\sim 30 \%$ of basal area was removed. That this method records interventions subsequent to the release of trees with FTG ratings of 3 and 4, but not those with FTG ratings of 0 and 1 also supports its application as a conservative indicator of canopy disturbance events. This method appears most successful at reconstructing canopy disturbances in trees with large release events from the removal of taller overstory trees, rather than disturbances that remove only subordinate trees.

\subsection{Ecological applications of the CST intervention method}

In addition to detecting large release events, intervention detection also is capable of reconstructing the magnitude of the effect on growth rates. The disturbance growth estimate reconstructed by the average of 12 CST interventions around the 1982 thinning event is of the same order of magnitude and only somewhat smaller than the growth rate difference between the 3 and 4 FTG trees and the 0 FTG trees. While this comparison is not an ideal control because of differences in average diameters of trees by FTG rating prior to the disturbance event, the similarities in these values support that intervention detection has the potential to determine the amount of subsequent growth in surviving trees resulting from a canopy disturbance event.

By altering light availability, canopy disturbance events can be viewed as environmental forcings that result in ecological responses in individual trees (sensuBriffa and Cook, 2008). These responses can now be quantified by tree-growth variables (i.e., growth rates, biomass, or carbon) in addition to the traditional population variables (e.g., number of trees experiencing a growth release or establishing after a disturbance event). These treegrowth variables will enable more detailed reconstructions of disturbance regimes for forests, providing managers with more information on the impact of past disturbance events.

To illustrate this point further, we return to the northern red oak series used as an example in Fig. 1. The tree's diameter was $77.4 \mathrm{~cm}$ when sampled in 2003 and the disturbance-growth index accounted for $15.7 \mathrm{~cm}$ of its diameter. Thus, this tree responded to this 1920 s disturbance by adding an additional basal area $0.192 \mathrm{~m}^{2}$, which is $41 \%$ of its total 2003 basal area of $0.471 \mathrm{~m}^{2}$. Using an allometric equation for whole tree northern red oak biomass developed by Monteith (1979) in Jenkins et al. (2004), we can further infer that this response added $1600 \mathrm{~kg}$ or approximately $800 \mathrm{~kg} \mathrm{C}$ of the total $2100 \mathrm{~kg} \mathrm{C}$ in this tree (assuming $49.6 \%$ carbon from Lamlon and Savidge, 2003) as a response to this canopy release.
Building on this framework of ecological forcings and growth responses, it is important to recognize that CST interventions are not limited to only detecting release events in ring-width series. CST interventions detect any unusual change in mean (step or level) and trend (slope) in a ring-width time series regardless of the type of disturbance initiating a growth change. For example, in these collections negative CST interventions are also frequently detected. When these negative CST interventions occur after earlier positive ones, they likely indicate the end of a transient growth pulse from a past canopy disturbance event with the return to closed-canopy conditions and ensuing tree competition (see also Druckenbrod (2005) for a documented example of canopy closure reducing growth rates at Hubbard Brook Experimental Forest). Similarly, Woods and Shanks (1959) investigated the growth response of chestnut oak, northern red oak, and hemlocks to the chestnut blight and observed that growth could be described progressively as a five stage process that was characterized overall by an increase in growth followed by a subsequent decline.

At the WVURF, negative CST interventions also preceded the 1982 thinning. Lamson et al. (1990) describe this stand as 54-years old and overstocked (sensuGingrich, 1967) at the time of treatment. While the complete history of this stand is not documented, it is possible that an increase in competition decreased growth rates beginning around the 1960s for this stand. It could also be that the 1960s drought, one of the intense in the northeastern US over the last 500 years (Pederson et al., 2013), could have played a role in reduced growth. Nevertheless, it appears that negative CST interventions may reconstruct suppressed growth episodes. An analysis of forests showing reduced growth, instead of release events, would evaluate this ability further.

\subsection{A new conceptual approach for dendroecological reconstructions of forest history}

Time series analysis with intervention detection has potential to provide a new conceptual approach for the reconstruction of canopy disturbance events from tree-ring widths. The application of time series analysis with intervention detection in this study presents a new mathematical approach that provides several advantages for dendroecology.

First, this method builds upon insights from dendroclimatological studies that account for the potentially confounding effects of age trends and autocorrelation prevalent within tree-ring widths. By applying procedures commonly used in dendroclimatology (Cook and Kairiukstis, 1990), this method operates on ring-width residuals that are independent samples through time enabling the use of statistical inference to detect canopy disturbance events.

Second, by using the central limit theorem, this method determines outliers only by the degree to which they are statistically unusual, not by using a priori assumptions of species-specific growth rates and release duration as input parameters to detect release events. This method may prove especially advantageous for species that are not as commonly studied from a tree-ring perspective, like Acer, Carya, Cinnamomum, Fraxinus, Lithocarpus, Magnolia, or Platanus.

Third, the window length on the residuals does not need to be limited to a particular and often arbitrary length, but can be set to encompass a range of years. This enables a more accurate determination of the duration of individual ecological responses (such as release events) to disturbances based upon the degree to which the age detrending and AR modeling fit the data. In this approach, an outlier can also be detected as early as the first few year of a series. For example, Appendix B (Supplemental Materials) shows a hemlock series with its first measured ring in 1535 and a suppression detected in 1538 . 
Fourth, since interventions can assume a variety of types (pulse, step, or trend) and combinations thereof, this approach allows for new research directions into the patterns of growth responses that best characterize particular ecological forcings on tree growth (e.g., insect defoliations, ice storms, pollution, canopy accession, etc.). Instead of simply taking the mean of a sequential set of AR residuals (implicitly weighting each residual equally with a constant of 1 ), one could apply varying weights to each residual in order to detect other ecological forcings characterized by different patterns. We imagine that there might be more than one approach to search for outliers within time series of ring widths and expect that methods like these will continue to improve.

Fifth, the ability to determine the magnitude of the growth response to an ecological forcing, such as a canopy disturbance, in terms of increased or reduced growth also potentially provides new research applications that could quantify the effects in terms of diameter increment, basal area increment, or carbon increment. Knowing the duration and magnitude of the growth response also enables detrending (by subtraction) of the disturbance event as originally conceptualized by the linear aggregate model of Graybill (1982) and Cook (1987). The resulting age and disturbance standardized series could be a new alternative for climate reconstructions in closed-canopy forests. Potentially, this form of a standardized series may be more useful than a standardized series in original units because the greater heteroscedasticity present in the latter may require additional detrending. More research is needed to explore the potential benefits of these standardized series compared to traditional methods of dendroclimatology in closed-canopy forests.

While this time series approach outlines new research applications and questions for dendroecology, and possibly dendroclimatology, in closed-canopy forests, it also brings attention to some methodological issues that will require further consideration as well. For example, it is possible that a prolonged, severe climatic event, like the 16th century megadrought (Stahle et al., 2000) that resulted in a 23-year drought in the greater New York City region between 1555 and 1577 (Pederson et al., 2013), could be identified as a negative CST intervention. Ecologically, this might still constitute a disturbance event (White and Pickett, 1985; Peters et al., 2011), but detrending this event would clearly impair the ability of the series to serve as a climate proxy. As another example, negative exponential curves or linear regressions are commonly applied to remove the age trend, but they may not be completely effective in closed-canopy forests because if the age trend is still present, a negative CST intervention may be identified early in the series when the tree may not have experienced suppressed growth. Problems such as these are present in other approaches to detrending stand dynamics in closed-canopy forests and, while ultimately it may be that no method will be able to completely reconstruct the multiple signals (age, climate, disturbance, etc.) embedded in one resulting growth series, this method shows great potential in isolating a disturbance signal from tree-ring widths.

\section{Acknowledgements}

This research was supported by a Rider University Summer Faculty Research Fellowship. The authors thank David Meko for use of subroutines from his Tree-Ring Matlab Toolbox, David South for archiving the 1941 USDA filmstrip on the chestnut blight, and Gary Miller, USDA Forest Service, who established the WVURF thinning experiment in 1982 and generously provided data for this paper. The authors also thank two anonymous reviewers for their comments on this manuscript.

\section{Appendix A. Supplementary material}

Supplementary data associated with this article can be found, in the online version, at http://dx.doi.org/10.1016/j.foreco.2013. 03.040.

\section{References}

Anagnostakis, S.L., Hillman, B., 1992. Evolution of the chestnut tree and its blight. Arnoldia 52, 3-10.

Andersen, T., Carstensen, J., Hernández-García, E., Duarte, C.M., 2009. Ecological thresholds and regime shifts: approaches to identification. Trends in Ecology \& Evolution 24, 49-57.

Black, B.A., Abrams, M., 2003. Use of boundary-line growth patterns as a basis for dendroecological release criteria. Ecological Applications 13, 1733-1749.

Blasing, T.J., Duvick, D.N., Cook, E.R., 1983. Filtering the effects of competition from ring-width series. Tree-Ring Bulletin 43, 19-31.

Box, G.E.P., Jenkins, G.M., 1970. Time Series Analysis: Forecasting and Control. Holden-Day, San Francisco.

Box, G.E.P., Tiao, G.C., 1975. Intervention analysis with applications to economic and environmental problems. Journal of American Statistical Association 70, 70-79.

Briffa, K., Cook, E.R., 2008. What are the Sources of Uncertainty in the Tree-Ring Data: How can they be Quantified and Represented? 2008 Paleoclimate Uncertainties Workshop White Paper, NOAA Paleoclimatology Program. Trieste, Italy, <http://www.ncdc.noaa.gov/paleo/reports/trieste2008/treerings.pdf $>$.

Buckley, B.M., Anchukaitis, K.J., Penny, D., Fletcher, R., Cook, E.R., Sano, M., Nam, L.C. Wichienkeeo, A., Minh, T.T., Hong, T.M., 2010. Climate as a contributing factor in the demise of Angkor, Cambodia. Proceedings for the National Academic Science of USA 107, 6748-6752.

Büntgen, U., Tegel, W., Nicolussi, K., McCormick, M., Frank, D., Trouet, V., Kaplan, J.O., Herzig, F., Heussner, K.-U., Wanner, H., Luterbacher, J., Esper, J., 2011. 2500 Years of European climate variability and human susceptibility. Science 331, $578-582$.

Chang, I., 1982. Outliers in Time Series. Ph.D. thesis, Department of Statistics, University of Wisconsin-Madison, Madison, Wis.

Cook, E.R., 1985. A Time Series Analysis Approach to Tree Ring Standardization. Ph.D. thesis, Department of Geosciences, University of Arizona, Tucson, Ariz

Cook, E.R., 1987. The decomposition of tree-ring series for environmental studies. Tree-Ring Bulletin 47, 37-59.

Cook, E.R., 1990. A conceptual linear aggregate model for tree rings. In: Cook, E.R. Kairiukstis, L.A. (Eds.), Methods of Dendrochronology. International Institute for Applied Systems Analysis, Netherlands, pp. 98-104.

Cook, E.R., Jacoby, G.C., 1977. Tree-ring drought relationships in the Hudson Valley, New York. Science 198, 399-401.

Cook, E.R., Kairiukstis, L.A. (Eds.), 1990. Methods of Dendrochronology. International Institute for Applied Systems Analysis, Netherlands.

Cook, E.R., Krusic, P.J., 2011. ARSTAN ver. 41d. <www.ldeo.columbia.edu/tree-ringlaboratory/resources/software>.

Cook, E.R., Peters, K., 1981. The smoothing spline: a new approach to standardizing forest interior tree-ring width series for dendroclimatic studies. Tree-Ring Bulletin 41, 45-53.

Cook, E.R., Peters, K., 1997. Calculating unbiased tree-ring indices for the study of climatic and environmental change. Holocene 7, 361-370.

Cook, E., Bird, T., Peterson, M., Barbetti, M., Buckley, B., D’Arrigo, R., Francey, R., 1992. Climatic change over the last millennium in Tasmania reconstructed from tree-rings. The Holocene 2, 205-217.

Davis, S.C., Hessl, A.E., Scott, C.J., Adams, M., Thomas, R.B., 2009. Forest carbon sequestration changes in response to timber harvest. Forest Ecology and Management 258, 2101-2109.

Downing, D.J., McLaughlin, S.B., 1990. Detecting shifts in radial growth by use of intervention detection. In: Cook, E.R., Kairiukstis, L.A. (Eds.), Methods of Dendrochronology. International Institute for Applied Systems Analysis, Netherlands, pp. 258-270.

Druckenbrod, D.L., 2005. Dendroecological reconstructions of forest disturbance history using time-series analysis with intervention detection. Canadian Journal of Forest Research 35, 868-876.

Fox, A.J., 1972. Outliers in time series. Journal of the Royal Statistical Society Series B 34, 350-363.

Fraver, S., White, A.S., 2005. Identifying growth releases in dendrochronological studies of forest disturbance. Canadian Journal of Forest Research 35, 16481656.

Fritts, H.C., 1976. Tree Rings and Climate. Academic Press, New York.

Gingrich, S.F., 1967. Measuring and evaluating stocking and stand density in upland hardwood forests in the central states. Forest Science 13, 38-53.

Gravatt, G.F., Gill, L.S., 1930. Chestnut Blight. USDA, Farmers’ Bulletin, 1641.

Graybill, D.A., 1982. Chronology development and analysis. In: Hughes, M.K., Kelly, P.M., Pilcher, J.R., LaMarche, V.C., Jr. (Eds.), Climate from Tree Rings. Cambridge University Press, Cambridge, pp. 21-28.

Guiot, J., 1986. ARMA techniques for modelling tree-ring response to climate and for reconstructing variations of paleoclimates. Ecological Modelling 33, 149-171. 
Henry, J.D., Swan, J.M.A., 1974. Reconstructing forest history from live and dead plant material - an approach to the study of forest succession in southwest New Hampshire. Ecology 55, 772-783.

Hoaglin, D.C., Mosteller, F., Tukey, J.W., 1983. Understanding Robust and Exploratory Data Analysis. Wiley, New York.

Holmes, R.L., 1983. Computer-assisted quality control in tree-ring dating and measurement. Tree-Ring Bulletin 44, 69-75.

Jenkins, J.C., Chojnacky, D.C., Heath, L.S., Birdsey, R.A., 2004. Comprehensive database of diameter-based biomass regressions for North American tree species. USDA, Forest Service, Northeastern Research Station. (General Technical, Report NE-319).

Kay, S.M., 1988. Modern Spectral Estimation: Theory and Application. Prentice Hall, New Jersey.

Lamlon, S.H., Savidge, R.A., 2003. A reassessment of carbon content in wood: variation within and between 41 North American species. Biomass and Bioenergy 25, 381-388.

Lamson, N.I., Smith, H.C., Perkey, A.W., Brock, S.M., 1990. Crown Releases Increase Growth of Crop Trees. USDA, Forest Service, Northeastern Research Station. (General Technical, Report NE-635).

Lorimer, C.G., Frelich, L.E., 1989. A methodology for estimating canopy disturbance frequency and intensity in dense temperate forests. Canadian Journal of Forest Research 19, 651-663.

Lund, R., Wang, X.L., Lu, Q.Q., Reeves, J., Gallagher, C., Feng, Y., 2007. Changepoint detection in periodic and autocorrelated time series. Journal of Climate 20 , 5178-5190.

Magnussen, S., Alfaro, R.I., 2012. Linking aerial survey data of forest insect defoliation and tree ring data to estimate forest level growth responses. Dendrochronologia 30, 287-294.

Mäkinen, H., 1997. Reducing the effects of disturbance on tree-ring data using intervention detection. Scandinavian Journal of Forest Research 12, 351-355.

Marshall, R., 1927. The Growth of Hemlock before and after Release from Suppression. Harvard University, Harvard Forest Bulletin No. 11. Harvard University Press, Cambridge, Massachusetts.

Mathworks, 2011. MATLAB release 2011a [computer program]. The Mathworks, Inc., Natick, Mass.

Monserud, R.A., 1986. Time-series analyses of tree-ring chronologies. For. Sci. 32, 349-372.

Monteith, D., 1979. Whole Tree Weight Tables for New York. State University of New York, Applied Forestry Research Institute Research Report 40. Syracuse.

Murrill, W.A., 1908. The spread of the chestnut disease. Journal of the New York Botanical Garden 9, 23-30.

Nowacki, G.J., Abrams, M.D., 1997. Radial-growth averaging criteria for reconstructing disturbance histories from presettlement-origin oaks. Ecological Monographs 67, 225-249.
Oliver, C.D., Stephens, E.P., 1977. Reconstruction of a mixed-species forest in central New England. Ecology 58, 562-572.

Pedersen, B.S., 1998. The role of stress in the mortality of Midwestern oaks as indicated by growth prior to death. Ecology 79, 79-93.

Pederson, N., Bell, A.R., Knight, T.A., Leland, C., Malcomb, N., Anchukaitis, K.J., Tackett, K., Scheff, J., Brice, A., Catron, B., Blozan, W., Riddle, J., 2012. A long-term perspective on a modern drought in the American Southeast. Environmental and Resources Letters 7, 014034.

Pederson, N., Bell, A.R., Cook, E.R., Lall, U., Devineni, N., Seager, R., Eggleston, K., Vranes, K.J., 2013. Is an epic pluvial masking the water insecurity of the greater New York city region? Journal of Climate 26, 1339-1354.

Peters, D.P.C., Lugo, A.E., Chapin, F.S. III, Pickett, S.T.A., Duniway, M., Rocha, A.V., Swanson, F.J., Laney, C., Jones, J., 2011. Cross-system comparisons elucidate disturbance complexities and generalities. Ecosphere 2, art81. doi: 10.1890/ ES11-00115.1.

Rentch, J.S., Desta, F., Miller, G.W., 2002. Climate, canopy disturbance, and radial growth averaging in a second-growth mixed-oak forest in West Virginia, USA. Canadian Journal of Forest Research 32, 915-927.

Rubino, D.L., McCarthy, B.C., 2004. Comparative analysis of dendroecological methods used to assess disturbance events. Dendrochronologia 21, 97-116.

Schlesinger, R.C., 1978. Increased growth of released white oak poles continues through two decades. Journal of Forestry 76, 726-727.

Speer, J.H., 2010. Fundamentals of Tree - Ring Research. U. of Arizona Press, Tucson, Arizona.

Stahle, D.W., Cleaveland, M.K., 1992. Reconstruction and analysis of spring rainfall over the southeastern US for the past 1000 years. Bulletin of the American Meteorological Society 73, 1947-1961.

Stahle, D.W., Cook, E.R., Cleaveland, M.K., Therrell, M.D., Meko, D.M., GrissinoMayer, H.D., Watson, E., Luckman, B.H., 2000. Tree-ring data document 16th century megadrought over North America. EOS 81 (121), 125.

Stephens, E.P., 1956. The uprooting of trees: a forest process. Soil Science Society of America Proceedings 20, 113-116.

USDA. 1941. Chestnut Blight. USDA Bureau of Plant Industry and Extension Service, Cooperating, Filmstrip.

White, P.S., Pickett, S.T.A., 1985. Natural disturbance and patch dynamics: an introduction. In: Pickett, S.T.A., White, P.S. (Eds.), The Ecology of Natural Disturbance and Patch Dynamics. Academic Press, New York, pp. 3-13.

Wilson, R.J.S., Luckman, B.H., Esper, J., 2005. A 500 year dendroclimatic reconstruction of spring-summer precipitation from the lower Bavarian Forest region, Germany. International Journal of Climatology 25, 611-630.

Woods, F.W., Shanks, R.E., 1959. Natural replacement of chestnut by other species in the Great Smoky Mountains National Park. Ecology 40, 349-361.

Zar, J.H., 1996. Biostatistical Analysis, third ed. Prentice-Hall, Upper Saddle River, New Jersey. 